\title{
Importancia actual de la oleoquímica en el sector industrial de tensioactivos
}

\author{
Por Carlos Gómez Herrera
}

\author{
Instituto de la Grasa (CSIC), Avda. Padre García Tejero, 4. 41012- Sevilla
}

\section{RESUMEN}

Importancia actual de la oleoquímica en el sector industrial de tensioactivos.

La oleoquímica es un sector industrial con aplicaciones múltiples e importantes desarrollos en el campo de los tensioactivos. En el presente artículo se dedican apartados a: A) fuentes de materias primas oleoquímicas, B) valorización de la oleoquímica en el campo de los tensioactivos, C) partes hidrófilas de los tensioactivos basadas en carbohidratos o en proteínas, D) ejemplos de biotensioactivos actualmente preparados a escala industrial, tales como ésteres de polioles, alquilpoliglucósidos, glucamidas, ésteres de sacarosa y lipoaminoácidos. La colaboración entre los sectores industriales de tensioactivos y de productos oleaginosos ha puesto en evidencia numerosos puntos fuertes. Muy probablemente, razones energéticas, económicas, ecológicas y sanitarias harán que esta colaboración se incremente en el futuro.

PALABRAS CLAVE: Cabeza hidrófila basada en carbohidratos - Cabeza hidrófila basada en proteína - Materia prima - Oleoquímica - Preparación a escala industrial Tensioactivo.

\section{SUMMARY}

Current importance of oleochemistry in the industrial sector of surfactants.

Oleochemistry is an industrial sector with various applications and important developments in the field of surfactans. In this article different parts are dedicated to: A) Sources of oleochemical raw materials; B) Valorization of the oleochemistry in the field of surfactants; C) Hydrophilic heads based on carbohydrates or proteins, D) Examples of surfactants currently prepared at industrial scale, such as esters of polyols, alkylpolyglucosides, glucamides and lipoaminoacids. Collaboration between industrial sectors of surfactants and oleaginous products has evidenced various strong points. Ecological, energetic, economical and sanitary reasons will probably increase this collaboration in the future.

KEY-WORDS: Hydrophilic head based on carbohydrates - Hydrophilic head based on proteins - Industrial scale preparation - Oleochemistry - Raw material - Surfactant.

\section{INTRODUCCIÓN}

La Real Academia Española, en la vigésima segunda edición (2001) de su"Diccionario de la Lengua Española" define el término "surfactante" como sus- tancia que reduce la tensión superficial de un líquido, y que sirve como agente humectante o detergente. Desde su creación en 1957, el Comité Español de la Detergencia emplea el término "tensioactivo" para designar a una sustancia dotada de actividad de supeficie (surface active agent). En la práctica, "surfactante" y "tensioactivo" son términos sinónimos.

La oleoquímica es un sector con aplicaciones múltiples e importantes desarrollos en los campos de biocarburantes (Montagne, 2006), biodisolventes (Lemor, 2006) y biolubricantes (Armangau-Batut, 2006). Entre estas aplicaciones merece destacarse el papel importante que la oleoquímica desempeña en el campo de los tensioactivos. (Guilbot, 2006; Bigorra 2008).

El término "biotensioactivo" suele aplicarse a productos extracelulalres producidos por microorganismos a partir de una diversidad de reservas de materias carbonadas neutras. Los "biotensioactivos" son biodegradables y biocompatibles, presentan una versatilidad de acciones biológicas, así como excelentes propiedades interfaciales. Se consideran tensioactivos "avanzados" para usos en industrias alimentarias, cosméticas, farmacéuticas y medioambientales.

En función de la naturaleza de las materias primas de partida, actualmente pueden distinguirse tres grandes clases de tensioactivos: a) los tensioactivos sintéticos no renovables, obtenidos a partir de sustratos de origen petroleoquímico; b) los tensioactivos renovables, preparados a partir de materias vegetales y animales; y c) los tensioactivos mixtos, con materias primas de ambos tipos. (Muñoz et al., 2007).

La oleoquímica constituye un sector de elección para acceder a una extensa gama de sustratos lipófilos naturales renovables bien adaptados a la planificación de nuevos tensioactivos, tanto renovables como mixtos. Ahora bien, la síntesis de nuevos compuestos tensioactivos muy distintos a los obtenidos a partir de estos sustratos naturales sigue investigándose a fondo. Como caso típico puede citarse el de tensioactivos no iónicos formados por condensación de óxido de propileno sobre compuestos heterocíclicos derivados de 2-hidroxiácidos. Estos tensioactivos presentan interés industrial potencial en la fabricación de medicamentos, cosméticos, plaguicidas o productos antimicrobianos. (Eissa y El-Sayed, 2007). 


\section{FUENTES DE MATERIAS PRIMAS OLEOQUÍMICAS}

Antes de los años 1970, los criterios principales para desarrollar un tensioactivo eran: a) rentabilidad industrial y económica, y b) eficacia durante su utilización. Este criterio condujo, al cabo de varios decenios, a la comercialización de tensioactivos procedentes de la petroleoquímica. Como ejemplos pueden citarse los alquilbencenosulfonatos lineales o ramificados, los parafinsulfonatos, los alfa-olefinsulfonatos, los alquilfenoles etoxilados, etc.

Las principales materias primas petroleoquímicas utilizadas son parafinas o hidrocarburos, etileno, propileno y benceno. Transformaciones adecuadas conducen a productos intermedios, tales como olefinas, alcoholes grasos o alquilbencenos. En una etapa posterior se incorporan las partes hidrófilas. Esta última etapa suele utilizar reacciones de sulfonación, de sulfatación y de alcoxilación.

Después de los años 1970, los dos criterios anteriormente citados (rentabilidad y eficacia) permanecen válidos, pero a estos se incorporan otros criterios relacionados con la presencia de restos de tensioactivos en el medio ambiente (toxicidad, ecotoxicidad, biodegradabilidad). Más adelante, esta toma de conciencia no hace más que aumentar y reforzarse con los conceptos de química verde y de desarrollo sostenible, así como también por la conocida reglamentación europea "REACH" (siglas de "Registration, Evaluation and Authorization of CHemicals" (Arriegui, 2006).

En este contexto, la valorización de sustratos lipófilos de origen natural ha recibido atención preferente, adquiriendo la oleoquímica gran importancia para la preparación de tensioactivos respetuosos con el medio ambiente (Behler et al., 2001).

La primera generación de sustratos lipófilos naturales corresponde a los ácidos grasos y sus ésteres metílicos, obtenidos respectivamente por procesos de saponificación o de metanolisis de aceites y grasas. Debe destacarse que ambos tipos de procesos dan glicerina como coproducto. Este polialcohol puede constituir una fuente de hidrofilia para sintetizar tensioactivos no iónicos, tales como éteres y ésteres de oligo- o de poli-gliceroles.

Según sea la composición intrínseca de los triacilgliceroles de partida, estos ácidos grasos y estos ésteres metílicos se caracterizan por cadenas de hidrocarburos lineales con un número par de átomos de carbono comprendido entre 8 y 22, así como por la presencia o ausencia de insaturación y/o de una función hidroxilo.

Además de la fabricación de jabón, conocida desde hace muchos siglos, otras transformaciones químicas de los ácidos grasos y de sus ésteres metílicos permiten, en una segunda etapa, aislar cadenas de hidrocarburos lineales con un número impar de átomos de carbono $\left(R \circ R^{\prime}\right)$ que se diferencian solamente de las especies químicas de partida por la naturaleza de su función química terminal.

La reducción de un ácido o de un éster conduce a los alcoholes correspondientes. El tratamiento de un alcohol con amoniaco produce aminas grasas. Estas son precursoras de los alqul-isocianatos. Los halogenuros de ácidos se obtienen por la reacción de un ácido graso con un agente halogenante adecuado.

Paralelamente a desarrollos industriales de otros sectores, la transformación de los ácidos grasos insaturados, tales como los ácidos oleico y ricinoleico, constituye una vía interesante para la síntesis de derivados con un número impar de átomos de carbono, como en los ácidos pelargónico $\left(\mathrm{CH}_{3} \cdot\left(\mathrm{CH}_{2}\right)_{7}-\mathrm{COOH}\right.$ y undecenoico $\left(\mathrm{CH}_{2}=\mathrm{CH}-\left(\mathrm{CH}_{2}\right)_{8}-\mathrm{COOH}\right)$ o una doble función como en los ácidos azelaico $\left(\mathrm{HOOC}-\left(\mathrm{CH}_{2}\right)_{7}\right.$ $\mathrm{COOH})$ o sebácico $\left(\mathrm{HOOC}-\left(\mathrm{CH}_{2}\right)_{8}-\mathrm{COOH}\right)$.

Mediante reacciones de dimerización pueden obtenerse nuevos sustratos lipófilos caracterizados por un número de átomos de carbono superior a 22, así como por la presencia de ramificaciones. A partir de alcoholes grasos lineales, puros o en mezcla, este método conduce a interesantes tipos de alcoholes $\alpha$ ramificados, conocidos como alcoholes de Guerbet $\left(\mathrm{R}^{\prime}-\mathrm{CH}_{2} \mathrm{CH}_{2}-\mathrm{CHR}^{\prime}-\mathrm{CH}_{2}-\mathrm{OH}\right)$. La dimerización de ácidos grasos insaturados procedentes del tall-oil permite formar ácidos dímeros acíclicos, monocíclicos o bicíclicos con cadenas de 36 átomos de carbono.

Esta rápida visión no exhaustiva de materias primas lipófilas derivadas de la oleoquímica demuestra la extensa gama de elección disponible para elaborar estructuras tensioactivas. La oleoquímica permite acceder a nuevas familias de moléculas tensioactivas renovables, que vayan sustituyendo progresivamente a los agentes de superficie de origen totalmente petroleoquímico.

Recientemente está presentando considerable interés el estudio de sustitutos de los etoxilados de alquilfenoles con cadenas muy ramificadas, para cumplir la nueva legislación europea referente a la conservación de la salud y del medio ambiente. Con este fin Bigorra et al (2005) están investigando sobre el uso de materias oleoquímicas naturales Deducen que, en algunos casos, alcoholes grasos con grados de etoxilación entre 10 y 30 pueden sustituir a los nonilfenoles etoxilados. Ahora bien, esta sustitución también podría conseguirse mediante el uso de nuevos alcoholes OXO, obtenidos por síntesis Fischer-Tropsch, con cadenas lineales o mono-metilsustituidas de 12 y 13 carbonos, a partir de $\alpha$-olefinas mediante hidroformilación (Schoenkaes et al. 2003).

Además de las ventajas medioambientales, el sector de oleaginosos supone una fuente de innovación importante La sinergia tensioactivo-oleoquímica, comprobada durante las tres últimas décadas, tiene un porvenir brillante, pero dependiente de las tendencias actuales en el campo de los biocarburantes (inversiones industriales, valorización de productos secundarios, etc.).

\section{VALORIZACIÓN DE LA OLEOQUÍMICA EN EL CAMPO DE LOS TENSIOACTIVOS}

El carácter anfifílico de un tensioactivo comunica a su estructura propiedades interfaciales específicas Estas propiedades se traducen concretamente por 
diferentes fenómenos que pueden valorizarse en diversas aplicaciones. Entre estas se encuentran descenso de tensión interfacial, exaltación de poder humectante, formación de micelas a concentraciones superiores a la micelar crítica para minimizar interacciones hidrófobas, solubilización, dispersión, emulsificación, etc. Por otra parte, los tensioactivos son capaces, en presencia de agua y ciertas condiciones, de formar fases líquido-cristalinas y liposomas.

Todas estas propiedades vienen directamente regidas por la estructura intrínseca del tensioactivo: geometría general, peso molecular, naturaleza del grupo de enlace químico intermedio (X) entre la cabeza hidrófila y la cola lipófila, presencia de grupos iónicos, balance hidrófilo-lipófilo (HLB), etc. Según la funcionalidad o funcionalidades de los sustratos de partida, así como según las estequiometrías presentes, será posible acceder a estructuras de tipo mono-, bi- y tricatenarias, así como a estructuras de los tipos geminis y bolaforma. Estas podrán presentar cabezas hidrófilas neutras, aniónicas, catiónicas, o zwitteriónicas, así como enlaces $\mathrm{X}$ de tipos éster, acetal, éter, amida o carbamato. La polaridad relativa de los sustratos de partida es primordial, pues ella orienta el HLB del tensioactivo, correlacionado con las propiedades finales del mismo.

De manera similar a las materias primas petroleoquímicas, los productos oleoquímicos permiten modular todos estos parámetros. También abre nuevas perspectivas, sobre todo con la utilización del ácido 12-hidroxiesteárico (derivado del ácido ricinoleico) para preparar tensioactivos polímeros. En efecto, la presencia simultánea de funciones de ácido carboxílico y de hidroxilo permite considerar, antes o durante el curso de la incorporación de la cabeza polar, reacciones de poliesterificación. Esta familia de compuestos presenta, en general, buenos resultados en la estabilización de emulsiones, debidos a sus masas moleculares relativamente elevadas (entre 3000 y $8000 \mathrm{~g} / \mathrm{mol}$ ) con respecto a un agente de superficie clásico.

Más allá de los aspectos estructurales y de aplicación, el interés de utilizar materias primas oleoquímicas reside en el carácter renovable de los recursos vegetales y animales. El agotamiento a corto o medio plazo de las reservas fósiles, así como la dificultad creciente para explotar nuevos yacimientos, refuerza cada vez más este argumento.

El éxito más destacado de la oleoquímica probablemente radica en las propiedades medioambientales de los tensioactivos renovables finales. Sus perfiles toxicológicos y ecotoxicológicos son, en la mayoría de los casos, muy satisfactorios y responden bien a las exigencias reglamentarias y económicas. Presentan elevadas biodegradabilidades rápida o intrínseca, baja toxicidad frente al hombre y los diferentes niveles tróficos del ecosistema (dafnias, algas, peces), así como una buena compatibilidad con elevadas tolerancias cutánea y ocular

\section{CONSIDERACIONES SOBRE LA PARTE HIDRÓFILA DEL TENSIOACTIVO}

\subsection{Fuentes de hidrofilia basadas en carbohidratos o sus derivados}

Los azúcares constituyen una materia prima polar importante para elaborar tensioactivos, al poseer un número importante de funciones hidroxilo capaces de formar redes de enlaces de hidrógeno en presencia de agua. Según su familia (hexosa o pentosa), así como sus pesos moleculares (mono-, di-, tri-, oligo- o polisacáridos), los azúcares permiten modular fácilmente la geometría general del tensioactivo, así como su HLB.

Actualmente las principales fuentes son de origen vegetal: trigo, maíz, patata, manioca, remolacha, caña de azúcar, alcaucil, achicoria, etc.

Por ejemplo, a partir del trigo se extrae almidón, formado por dos homopolímeros de glucosa: la amilosa, polímero lineal que solo presenta enlaces glucosídicos $\alpha-1,4$, y la amilopectina, polímero ramificado presentando enlaces glucosídicos $\alpha-1,4$ y $\alpha-1,6$. Después de una hidrólisis, química o enzimática, el polímero pasa a glucosa. Una hidrólisis controlada permite obtener oligo-glucosas (maltodextrinas) que presentan un número variable de unidades de glucosa (Figura 1).

La industria silvícola es una fuente importante de azúcares. La celulosa y la hemicelulosa forman

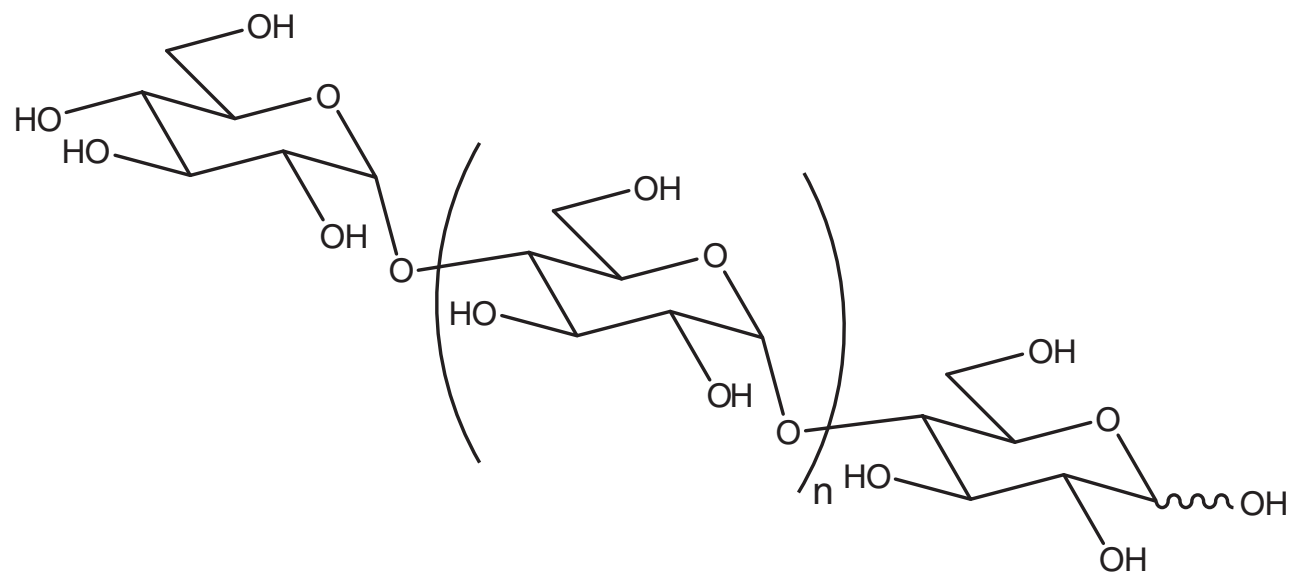

Figura 1

Maltodextrina (oligoglucosa). 
una estructura fibrosa extracelular que sirve de esqueleto a las plantas La celulosa es un homopolímero lineal de glucosa que no presenta enlaces glucosídicos $\alpha-1,4$, sino enlaces $\beta-1,4$. La hemicelulosa es un heteropolímero más complejo, más o menos rico en xilosa y arabinosa. Después de las etapas de extracción, hidrólisis y purificación, pueden obtenerse estos dos monosacáridos de la familia de las pentosas.

Las raíces de achicoria y los tubérculos de alcaucil se utilizan en la fabricación de diferentes grados de inulina. La inulina es un polímero de fructosa de la familia de los fructanos, que se caracteriza por enlaces glucosídicos $\beta-2,1$, grados de polimerización comprendidos entre 2 y 100 y la presencia de un grupo de glucosa terminal. La hidrólisis total o parcial de estos polímeros de inulina conduce a oligofructosas o a fructosa pura.

Las transformaciones químicas, enzimáticas o biotecnológicas de los mono., di- y oligosacáridos antes citados pueden conducir en una segunda etapa a polioles tales como el sorbitol y el xilitol, así como a estructuras sacarídicas macrocíclicas como las ciclodextrinas.

Aplicando información filogenética, Konishi et al. (2008) han encontrado que la levadura Candida batistae, a partir de aceite de oliva y glucosa como únicas fuentes de carbono, produce la especie química derivada de soforosa cuyo nombre es ácido18-L-(\{2'-O- $\beta$-D-glucopiranosil- $\beta$-D-glucopiranosil\}-oxi-)octadecenoico,6",6"-di-O-acetato. Esta especie, dotada de alta hidrofilia, presenta eficacia para eliminar triacilgliceroles similar a las del dodecilsulfato sódico, los alquilbencenosufonatos de cadena lineal.y el dodecil - $\beta$-maltosido. Otras levaduras producen soforolípidos preferentemente en forma de lactonas.

\subsection{Fuentes de hidrofilia procedentes de derivados proteicos}

Los aminoácidos y los hidrolizados de proteínas son buenos candidatos para actuar como cabezas polares de tensioactivos renovables. Después de su lipofilización, se transforman respectivamente en lipoaminoácidos y en lipoproteínas que presentan uno o varios grupos hidrófilos aniónicos de tipo carboxilato.

Existen unos veinte aminoácidos naturales, agrupados en función de la naturaleza de su cadena lateral: A) cadena no polar neutra (fenilalanina, leucina, isoleucina, prolina, valina, etc.); B) cadena polar básica (arginina y lisina); y C) cadena polar ácida (ácidos glutámico y aspártico) Además de su extracción de productos naturales, existen diferentes métodos químicos y enzimáticos para su síntesis.

La composición de los hidrolizados de proteínas depende del aminograma de las materias primas de partida, así como de las condiciones de hidrólisis aplicadas. Las proteínas vegetales proceden frecuentemente de "coproductos" de la transformación de plantas ampliamente cultivadas. Como ejemplos pueden citarse el gluten de trigo o de maíz procedente de las fábricas de almidón, así como los concentrados proteicos o turtós de los vegetales oleaginosos separados después de la extracción de su aceite. Recientemente Ferreyra et al. (2007) estudiaron las propiedades emulsionantes de las proteínas de harina de cacahuete, muy abundantes al ser subproductos de una semilla oleaginosa cultivada a gran escala. Dichas propiedades dependen directamente de la fase acuosa de la emulsión ( $\mathrm{pH}$; solubilidad). Su incorporación a formulaciones alimentarias, farmacéuticas y cosméticas puede favorecer su comportamiento reológico.

Las proteínas animales suelen ser extractos (colágeno, gelatina, albúmina, caseína, etc,). Son más caras que las proteínas vegetales. La tendencia actual no valora la utilización de esta fuente de hidrofilia en usos cosméticos o alimentarios. Las proteínas animales pueden sufrir una imagen negativa relacionada con la encefalopatía espongiforme bovina (mal de la vaca loca).

La utilización a escala industrial de péptidos u oligopéptidos está poco extendida. El coste de fabricación de este tipo de materias primas (síntesis peptídica con múltiples etapas) resulta elevado para la preparación de tensioactivos destinados a especialidades (lipopéptidos). Sin embargo, se puede citar el aspartamo (dipéptido formado por un grupo de ácido aspártico y un grupo de fenilalanina esterificado). Este dipéptido se valora en industria agroalimentaria por sus propiedades edulcorantes. Su precio podría adaptarse a ciertas aplicaciones de alto valor añadido, pero la incorporación de cadenas lipófilas quita mucha estabilidad.

\section{EJEMPLOS DE TENSIOACTIVOS RENOVABLES PREPARADOS A ESCALA INDUSTRIAL}

En este apartado se describen sucintamente los procedimientos operatorios que permiten crear, en condiciones eficaces y respetuosas con el medio ambiente, el enlace covalente entre las partes hidrófila y lipófila del tensioactivo renovable.

\subsection{Tensioactivos sacarídicos}

Los ésteres de polioles (Figura 2) han sido desrrollados desde hace varios decenios. Se obtienen por esterificación de un poliol, como sorbitol o manitol, en presencia de un catalizador, con ácidos grasos puros o mezclas de los mismos. Las reacciones se producen, sin disolvente, por dispersión del poliol en ácido graso fundido. Los subproductos son agua y un decantado que puede reciclarse. Las reacciones de deshidratación intramolecular, que se producen previamente a la esterificación, conducen a una mezcla de especies químicas (sorbitol, sorbitano. etc.). Según la estequiometría del ácido graso y de la reactividad de las diferentes funciones alcohólicas, se formarán mono-, di-, tri- o incluso tetra-ésteres. 


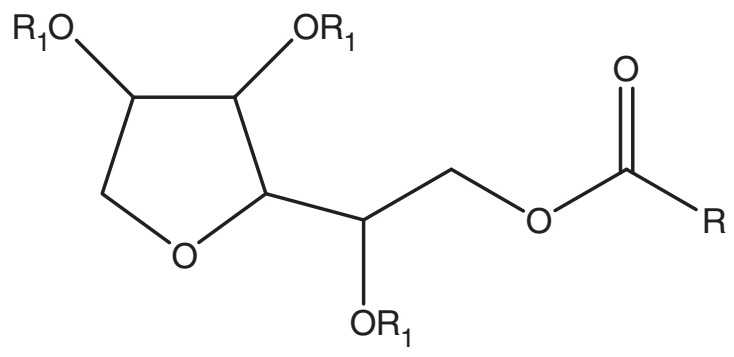

Figura 2

Éster de sorbitano.

Estos ésteres de polioles son emulsionantes lipófilos con un HLB entre 2 y 8 . Se utilizan en cosmética y en sanidad animal (vacunas de bovinos y de cerdos contra la fiebre aftosa). Su biodegradabilidad y su ecotoxicidad son satisfactorias. En la mayoría de los casos se someten a etoxilación para ampliar el intervalo de HLB hacia valores más altos y optimizar las estabilidades de las emulsiones.

Actualmente, los mejores ejemplos de la glucoquímica son los llamados alquilpoliglucósidos (APG), obtenidos a partir de glucosa cristalizada y de un alcohol graso puro o de una mezcla de estos ácidos. (Milius et al., 1995) (Figura 3).

Las reacciones de glucosilación se conducen según las condiciones de Fischer que consisten en activar la posición anomérica del azúcar por un catalizador ácido e ir eliminando el agua a medida que se forma. Las reacciones se realizan sin disolvente, con la glucosa en suspensión en un exceso del alcohol graso fundido. Los subproductos formados son agua y un residuo de azúcar.

El injerto del alcohol sobre el azúcar activado viene acompañado frecuentemente por una polimerización de la cabeza polar sacarídica. Los grados de polimerización ("DP" en la figura 3), comprendidos entre 1,3 y 1,6, dependen directamente de las condiciones experimentales y pueden modular sensiblemente el HLB del alquilpoliglucósido final. Al no estar estereocontroladas las reacciones, debe tenerse en cuenta que un alquilpoliglucósido es una mezcla de estereoisómeros ( $\alpha, \beta$, furano-, pirano-) que no se purifica por razones económicas. Recientemente Nestor et al. (2008) han estudiado el empleo de un tensioactivo polimérico derivado de carbohidratos para estabilizar dispersiones coloidales. Al fin del proceso, el exceso de alcohol se deja en el medio o se evapora. Para cadenas lipófilas largas (14 o más átomos de carbono) el alquilpoliglucósido presenta propiedades emulsio- nantes "agua en aceite". Para cadenas más cortas, se comercializa en disolución acuosa con propiedades solubilizantes, humectantes y espumantes. Los alquilpoliglucósidos están introducidos principalmente en formulaciones cosméticas (cremas, geles, productos para ducha) o detergentes (lavavajillas). Son biodegradables y carecen de ecotoxicidad.

También es previsible la glucosilación de los alcoholes de Guerbet. Se puede citar la preparación de octil-dodecil-xiloside, valorizado en cosmética como coemulsionante "agua en aceite". Su originalidad se basa, por una parte, en la presencia de una cabeza xilosídica y, por otra parte, en su aspecto líquido que permite usarlo para emulsificaciones en frío. En una segunda fase, los costes de fabricación de los alquilpoliglucósidos permiten su utilización como materias primas en nuevas formulaciones (Milius y Brancq, 1995). Los principales ejemplos comerciales son los ésteres de metilglucosidos y los alquilpoliglucosidos aniónicos (hemisulfosuccinatos, citratos, tatratos) o catiónicos.

Las glucamidas se sintetizan en dos etapas: a) reacción entre glucosa y metilamina, y b) amidificación de la $\mathrm{N}$-metilglucamina intermedia con un éster metílico. A diferencia de los alquilpoliglucósidos, las glucamidas solo tienen un mol de glucosa y, por tanto, son menos hidrosolubles (Figura 4). Una acetilación opcional de la N-metilglucamina residual permite evitar las trazas de nitrosaminas en el producto final. Se utilizan mayoritariamente en detergencia con aplicaciones y comportamiento medioambiental similares a los de los alquilpoliglucósidos.

Los ésteres de sacarosa constituyen una interesante clase de tensioactivos renovables derivados de carbohidratos. La principal dificultad, debida al elevado número de funciones hidroxilo del azúcar de partida, radica principalmente en la obtención de derivados monosustituidos. Para obtener regioselectividad existen diversos métodos, tales como catálisis enzimáticas, acilación por cloruros de ácido, purificación por cristalización o por extracción, etc. La ruta mejor adaptada a la escala industrial es actualmente la transesterificación seguida por una purificación de los monoésteres. Estos compuestos se utilizan como emulsionantes en alimentación y en cosmética.

La obtención de tensioactivos glucosídicos con una fuerte hidrofilia puede alcanzarse mediante funcionalización de oligosacáridos (con grado de polimerización superior a 2). Su HLB dependerá de

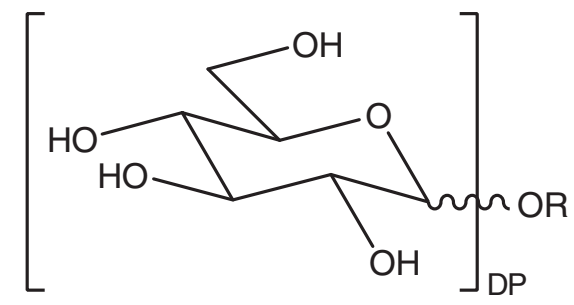

Figura 3

Alquilpoliglucósido.<smiles>[R]C(=O)N(C)C[C@@H](O)[C@H](O)[C@H](O)[C@H](O)CO</smiles>

Figura 4

Glucamida. 
este grado en el oligosacárido de partida, así como del número de cadenas lipófilas injertadas. Un ejemplo, recientemente comercializado en cosméti$\mathrm{ca}$, son los alquilcarbamatos de oligofructosa obtenidos a partir de alquilisocianatos y de hidrolizados de inulina.

\subsection{Lipoaminoácidos}

Los lipoaminoácidos, y más generalmente las lipoproteínas, se obtienen en las condiciones de Schotten-Baumann mediante acilación de uno o varios residuos de $\alpha$-aminoácidos con un cloruro de ácido en presencia de una base (Figura 5). Estas reacciones se producen en un medio acuoso o hidroorgánico (agua-alcohol, agua-acetona) según sea la solubilidad inicial del derivado proteico de partida.

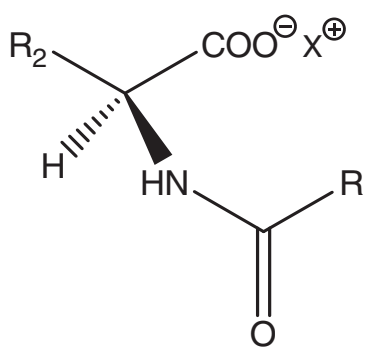

Figura 5

Lipoaminoácido.

En el caso de un aminoácido que presenta una función reactiva sobre una cadena lateral (amina, hidroxilo o guanidina), las condiciones anteriores no permiten una acilación regioselectiva, caracterizándose los medios reaccionantes por ser mezclas de derivados mono- y di-acilados. Contrariamente a los hidrolizados de proteínas animales o vegetales, la utilización de aminoácidos limita los problemas de reproducibilidad en lo referente a olor, color y eficacia de sus aplicaciones.

Al finalizar la acilación, son posibles dos alternativas. La primera consiste en mantener el $\mathrm{pH}$ del medio final en las proximidades de 7; siendo comercializados los lipoaminoácidos en disolución acuosa. Las propiedades espumantes de estos tensioactivos aniónicos se valoran en cosmética para formular geles de ducha, lociones limpiadoras y champús. La segunda alternativa consiste en la precipitación del lipoaminoácido acidificando la mezcla reaccionante a $\mathrm{pH} 2$, seguida por varias operaciones de lavado. Este método permite eliminar todas las sales producidas durante la acilación $y$, por consiguiente, aislar un lipoaminoácido en forma de un polvo de alta pureza.

Si se tiene en cuenta el aumento de coste provocado por las etapas de filtración y de secado, esta vía es muy adecuada para poner a punto productos cosméticos activos. Los aminoácidos más usados son glicina, fenilalanina, prolina e hidroxiprolina.. Las cadenas acílícas más frecuentes son las de octanoilo, undecenoilo, lauroilo y palmitoilo. Algunos se utilizan en aplicaciones cosméticas.

Siguiendo la misma estrategia, pueden usarse dicloruros de ácidos dicarboxílicos (azelaico, sebácico) en reacciones de acilación de aminoácidos (Figura 6). Su doble funcionalidad permite prever la preparación de lipoaminoácidos bolaformes (azeloil-diglicinatos). La baja hidrosolubilidad del ácido azelaico, utilizado en cosmética por sus propiedades bacteriostáticas, bactericidas y reguladoras de sebo, se ha mejorado injertando un grupo de glicinato de potasio a cada uno de sus extremos. (Maramaldi y Esposito, 2002).

\section{6. ÚLTIMOS AVANCES}

Recientemente Rangsansand et al. (2008) han investigado sobre la mejora de las propiedades funcionales de las proteínas, mejora que se consigue haciéndolas conjugar con un monosacárido según la reacción de Maillard.

\section{$\mathrm{Rs}-\mathrm{CH}(\mathrm{OH})-\mathrm{CHO}+\mathrm{Rp}-\mathrm{NH}_{2}$}

Esta reacción es un conjunto de procesos no enzimáticos que conduce a un enlace entre el grupo aldehído del monosacárido (cuyo resto $\mathrm{CH}_{2} \mathrm{OH}-(\mathrm{CHOH})_{3}$ - se representa por Rs-) y un grupo amino primario de la proteína (cuyo resto corresponde a Rp), formándose mezclas de compuestos de Amadori de tipo 1-amino-1-deoxicetosa. Como ejemplos típicos pueden citarse los siguientes:

$$
\begin{gathered}
\mathrm{Rp}-\mathrm{NH}-\mathrm{CH}=\mathrm{C}(\mathrm{OH})-\mathrm{R}_{\mathrm{S}}: \\
\mathrm{Rp}-\mathrm{N}=\mathrm{CH}-\mathrm{CH}(\mathrm{OH})-\mathrm{Rs} \text { y } \mathrm{Rp}-\mathrm{NH}-\mathrm{CH}_{2}-\mathrm{CO}-\mathrm{R}_{\mathrm{S}}
\end{gathered}
$$

Para favorecer el poder emulsionante de estos compuestos se les incorpora polisacáridos, cuyas

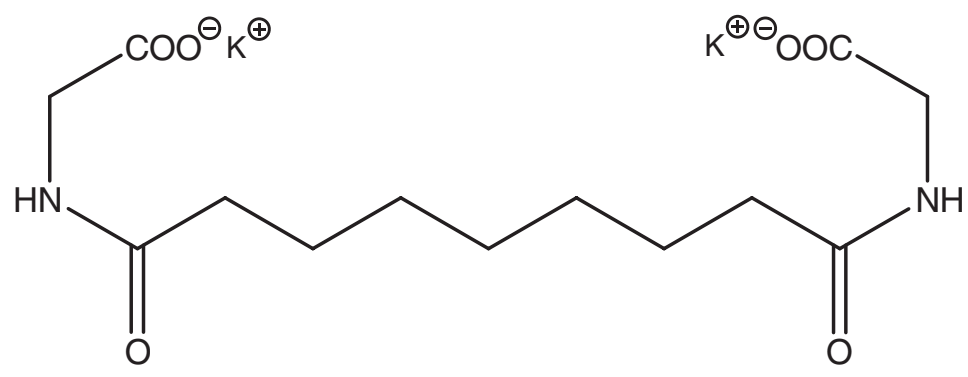

Figura 6

Azeloil-diglicinato dipotásico. 
cadenas, al adsorberse en las interfacies $\mathrm{W}-\mathrm{A}$, penetran en la fase acuosa, dificultando la floculación y la coalescencia. Puede mejorarse el poder emulsionante esterificando el grupo alcohólico primario terminal libre del carbohidrato con ácido graso.

\section{CONCLUSIÓN}

La oleoquímica desempeña un papel primordial en el campo de los tensioactivos. Constituye actualmente el único camino para fabricar agentes de superficie totalmente de origen natural.

El amplio margen de cadenas de hidrocarburos ofrecido por la oleoquímica se adapta bien a la lipofilización de polioles, azúcares o derivados proteicos. Esta facilidad de elección permite modular diversos parámetros, tales como el HLB o la naturaleza del grupo de enlace químico intermedio (X) entre cabeza hidrófila y cola lipófila, así como las propiedades quimico-físicas y las aplicaciones de los tensioactivos resultantes. En este contexto, la oleoquímica constituye una fuente de innovación importante para desarrollar nuevos tensioactivos eficaces y respetuosos con el medio ambiente.

A diferencia de las materias primas petroleoquímicas, que originan hoy numerosos interrogantes, las disponibilidades de materias oleoquímicas no plantean problemas similares y vienen apoyadas por los numerosos caminos de desarrollo previstos paralelamente en otros sectores (biocarburantes, biodisolventes, biolubricantes).

En resumen, la colaboración entre los sectores de tensioactivos y de productos oleaginosos ha puesto en evidencia numerosos puntos fuertes, Muy probablemente, esta colaboración se incrementará en el futuro.

\section{REFERENCIAS}

Armangaud Batut R. 2006. Contribution des corps gras au développement durable: solutions énergétiques et chimiques. OCL 13 187-189.

Arriegui C. 2006."The REACH Proposal Legislative Development and Industry Preparation" Jorn. Com. Esp. Deterg. 36 151-163.
Behler A, Biermann M, Hill K, Raths HC, Saint Victor ME, Uphues G. 2001. En Industrial surfactant syntheses. Surfactant science series, Marcel Dekker Inc. New York.

Bigorra J, Brener W, Heldt S, Llaurado LI. 2005. Ethoxylated natural fatty alcohol derivatives. Alternative products to ethoxylated nonylphenols. Jorn. Com. Esp. Deterg. 35, 155-162.

Bigorra J, Möfer R. 2008. Biomass based green chemistry - Sustainable solutions for modern economics. Jorn. Com. Esp. Deterg. 38 179-200.

Eissa Am F, El-Sayed R. 2007. Synthesis and evaluation of $\alpha$-hydroxy fatty acid-derived heterocyclic compounds with potential industrial interest. Grasas y Aceites 58, 20-28.

Ferreyra JC, Kuskoski EM, Bordignon Luiz MT, Barrera Arellano, D, Fett R. 2007. Propiedades emulsificantes y espumantes de las proteínas de harina de cacahuete (Arachis hypogea Lineau) Grasas y Aceites 58, 264-269.

Guilbot J. 2006. Importance des corps gras dans le domaine des tensioactifs. OCL 13, 178-186.

Konishi M, Fukuoka T, Morita T, Imura T, Kitamoto D. 2008. Production of new types of sophorolipids by Candida batistae. J. Oleo Sci. 57, 359-369.

Lemor A. 2006. Directives COV (Composés Organiques Volatiles) et alternative lipochimiques: peintures, encres, nettoyage, dégraissage. OCL 13, 171-77.

Maramaldi G, Esposito MA. 2002. Potassium azeloyl diglycinate: A multifunctional skin lightener, Cosmetics \& Toiletries 43-50.

Milius A, Brancq B. 1995. Alkylpolyglycosides: les nouvelles orientations. OCL 2, 177-182.

Montagne X. 2006. Biocarburants - les carburants liquides. La chimie verte. Lavoisier, Paris, 419-445.

Muñoz J, Alfaro MC, Zapata I. 2007. Avances en la formulación de emulsiones Grasas y Aceites 58, 64-73.

Nestor J, Obiols-Rabasa M, Esquena J, Solans C, Levecke B, Booten K, Tadros ThF, Luckhan PF, Musoke M. 2008. Study of colloidal dispersions stabilized by a sugar derivative polymeric surfactant. Jorn. Com. Esp. Deterg. 38, 101-110.

Rangsansad J, Cheetangdee N, Kinoshita N, Fukuda K. 2008. Bovine serum albumin - sugar conjugates through the Maillard reaction: Effects on interfacial behavior and emulsifying ability. J. Oleo Sci. 57, 539-547.

Schoenkaes L, Brock M, Goronyane B, Grothe R. Maharaj S, Mayer U, Matheson L. 2003. Surfactants based on novel oxo alcohols. Jorn. Com. Esp. Deterg. 33, 155-163.

Recibido: $19 / 2 / 09$ Aceptado: 9/3/09 